\title{
Combining TRMM and Surface Observations of Precipitation: Technique and Validation over South America
}

\author{
José Roberto Rozante And Demerval SoARes Moreira \\ Center for Weather Forecasts and Climate Studies, CPTEC/INPE, São Paulo, Brazil \\ Luis Gustavo G. DE GonCAlves \\ Hydrological Sciences Branch, NASA Goddard Space Flight Center, Greenbelt, Maryland, \\ and Earth System Interdisciplinary Center, University of Maryland, College Park, College Park, Maryland \\ DANIEL A. VILA \\ Cooperative Institute of Climate Studies, and Earth System Interdisciplinary Center, University of Maryland, College Park, \\ College Park, Maryland
}

(Manuscript received 26 June 2009, in final form 13 January 2010)

\begin{abstract}
The measure of atmospheric model performance is highly dependent on the quality of the observations used in the evaluation process. In the particular case of operational forecast centers, large-scale datasets must be made available in a timely manner for continuous assessment of model results. Numerical models and surface observations usually work at distinct spatial scales (i.e., areal average in a regular grid versus point measurements), making direct comparison difficult. Alternatively, interpolation methods are employed for mapping observational data to regular grids and vice versa. A new technique (hereafter called MERGE) to combine Tropical Rainfall Measuring Mission (TRMM) satellite precipitation estimates with surface observations over the South American continent is proposed and its performance is evaluated for the 2007 summer and winter seasons. Two different approaches for the evaluation of the performance of this product against observations were tested: a cross-validation subsampling of the entire continent and another subsampling of only areas with sparse observations. Results show that over areas with a high density of observations, the MERGE technique's performance is equivalent to that of simply averaging the stations within the grid boxes. However, over areas with sparse observations, MERGE shows superior results.
\end{abstract}

\section{Introduction}

Operational climate and weather forecast centers routinely evaluate numerical models at regularly spaced grid points. Generally, surface observations are considered "the truth" in such model validations. However, in most cases observations and numerical model output are presented at distinct spatial and temporal scales. Furthermore, surface observations are irregularly spatially distributed and represent environmental characteristics only at a single point and its nearby surroundings.

Corresponding author address: José Roberto Rozante, Center for Weather Forecasts and Climate Studies, CPTEC/INPE, Rodovia Presidente Dutra KM 40, Cachoeira Paulista, SP, CEP 12 630-000, Brazil.

E-mail: roberto.rozante@cptec.inpe.br
Numerical model output, on the other hand, is the result of averaged fields at regularly spaced grid points.

Therefore, atmospheric variables such as precipitation, when represented at regularly spaced grid points, are valuable sources of information for identifying regions of systematic error in climate and weather forecast model results. South America represents a challenging region for the evaluation of numerical model precipitation due to its sparse and irregular observational network, which is biased toward populated centers near the edge of the continent or along the major river courses. The low density of observations toward the center of the continent and nonexistent stations over the ocean makes precipitation interpolated to regular grids generally a poor quality product. Therefore, the low level of confidence in the interpolated observed datasets compromises the numerical model validation procedure. Remotely 
sensed estimates of precipitation inferred, for example, from infrared cloud-top temperatures may provide a means of filling gaps between surface observations in remote regions. However, the calibration and validation of such remotely sensed estimates must be carefully examined because ground-based observations are so sparse (de Goncalves et al. 2006).

The use of precipitation estimates from the Tropical Rainfall Measuring Mission (TRMM) satellite has been extensively employed for numerical model evaluation over the South American continent (Valverde Ramírez 2003; de Goncalves et al. 2006; Rozante and Cavalcanti 2008). TRMM is a joint project between the National Aeronautics and Space Administration (NASA) and the Japan Aerospace Exploration Agency (JAXA), launched in November 1997 with the specific objectives of studying and monitoring tropical rainfall (Kummerow et al. 2000). The TRMM project provides various products through a combination of different satellite sensors, for example, the TRMM Microwave Imager (TMI), the Precipitation Radar (PR), and the Visible and Infrared Radiometer (VIRS). The 3B42RT product uses microwave precipitation estimates from the TMI sensor adjusted by the cloud vertical structure obtained from the PR sensor, as well as geosynchronous infrared data. A more detailed description of the 3B42RT product can be found in Huffman et al. 2007. The 3B42RT product is available at $0.25^{\circ}$ spatial resolution every $3 \mathrm{~h}$. Only a few merged products combining TRMM and observations have been produced over South America (Huffman et al. 2007; Vila et al. 2009). Although these have shown good results, they are not entirely suitable for everyday model evaluation at operational centers where information needs to rapidly be made available.

Although the TRMM products are highly valuable for numerical model validation, systematic errors are observed, in particular on the east coast of the northeastern region of Brazil. Precipitation is underestimated in that region due to warm clouds, as has been shown by Huffman et al. (2007), Franchito et al. (2009), and Vila et al. (2009). Another such area is the junction of Argentina, Paraguay, and Brazil, where precipitation is overestimated due to cold top clouds, as shown by Rozante and Calcalcanti (2008).

To minimize problems with interpolation in regions of low-density observation networks, as well as under- and overestimates in the TRMM product, a combination of rain gauge datasets [Global Telecommunications System (GTS), automatic stations, and various agencies in South America] and the real-time TRMM precipitation (3B42RT) is proposed, and a higher quality gridded dataset $\left(0.25^{\circ}\right.$ spatial resolution) for operational numerical model evaluation is produced.

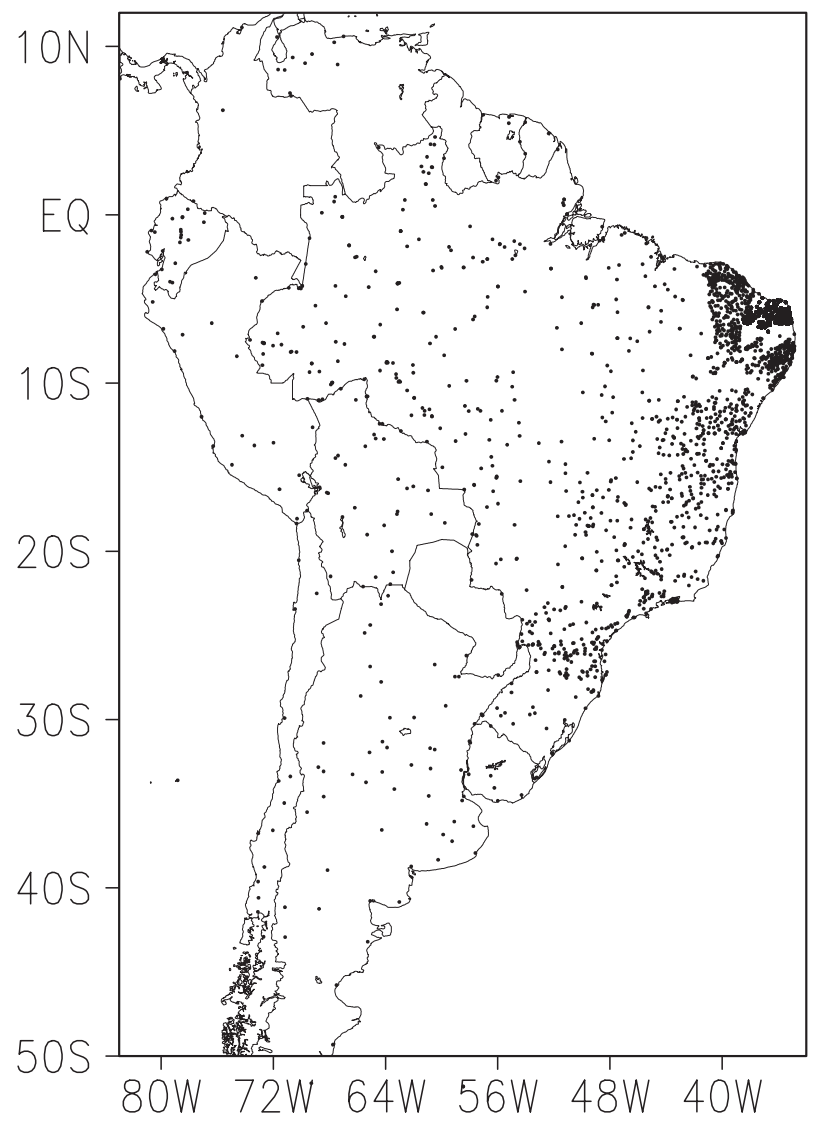

FIG. 1. Spatial distribution of rain gauges from different sources (i.e., GTS, regional and local agencies, and automated stations) over South America. Source data: Instituto Nacional de Meteorologia (INMET), CPTEC/INPE, and regional meteorological centers.

\section{Methodology}

\section{a. Datasets}

The Center for Weather Forecasts and Climate Studies [Centro de Previsão de Tempo e Estudos Climáticos (CPTEC) in Portuguese], a division of the Brazilian National Institute for Space Research [Instituto Nacional de Pesquisas Espaciais (INPE) in Portuguese], maintains a database of approximately 1500 surface stations that are regularly reported from the GTS network, automatic surface observation stations (ASOSs), and observations routinely collected by regional agencies in Brazil. The spatial distribution of this observation network is very irregular, as shown in Fig. 1. The majority of the surface stations in Brazil are concentrated toward the eastern portion of the continent of South America. Toward the center of the continent, the network density decreases drastically in both the north and south.

Prior to the merged precipitation product described in this study, CPTEC/INPE evaluated its operational models using interpolated fields from surface stations only 


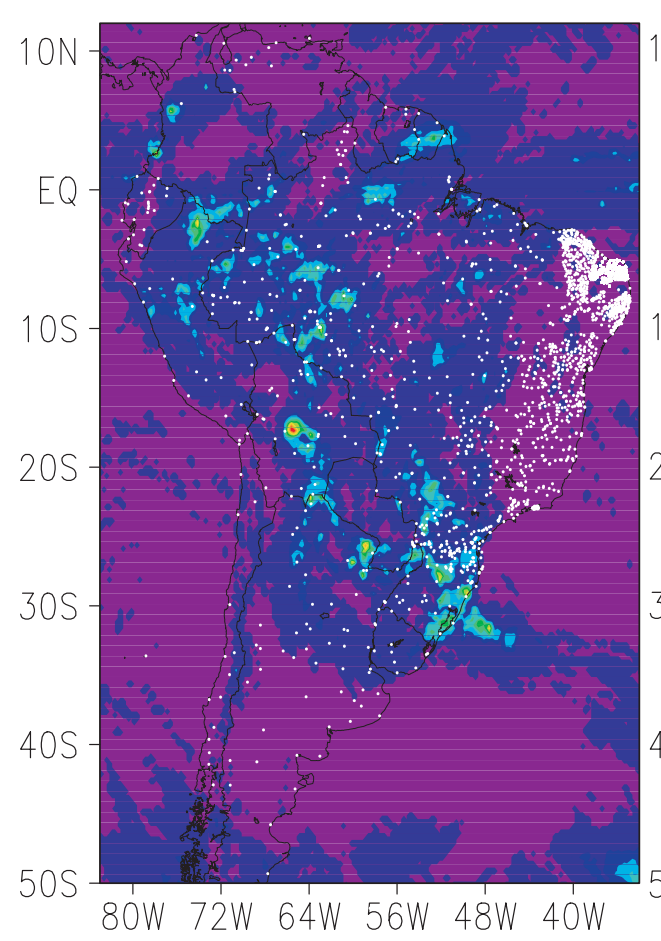

(a)

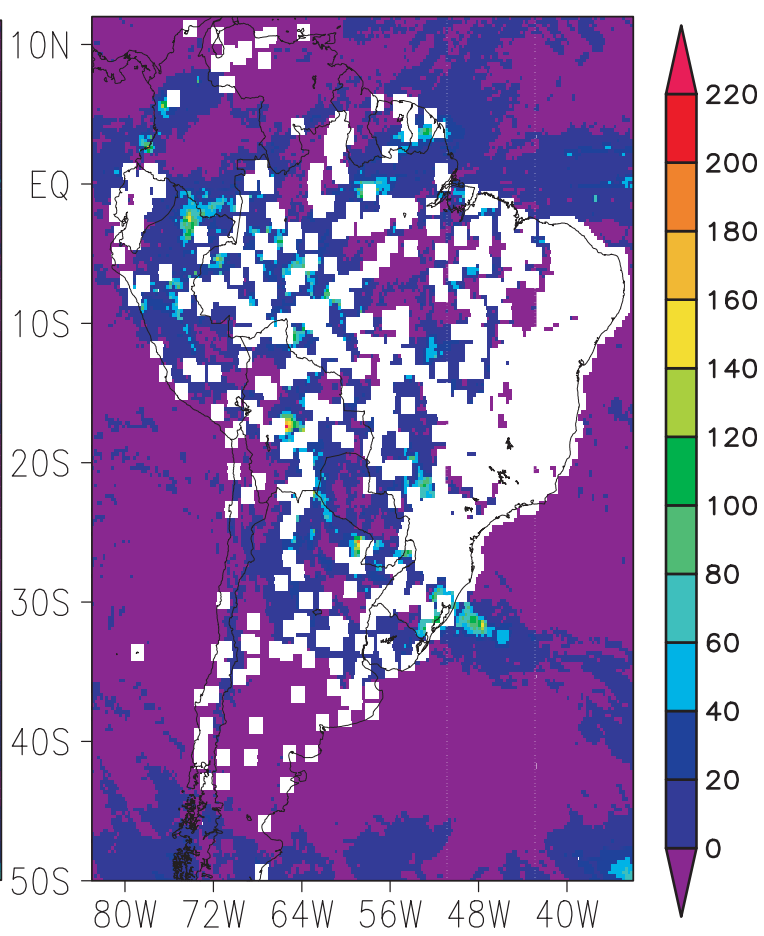

(b)

FIG. 2. The TRMM 24-h accumulated precipitation estimate (shaded) for 8 Mar 2003. (a) White dots represent the reporting rain gauges on that particular day. (b) White squares represent the $0.25^{\circ} \mathrm{TRMM}$ grid boxes near the rain gauges shown in (a).

(approximately 1500 daily reporting stations, as shown in Fig. 1). In this study, the satellite product TRMM 3B42RT is used due to its near-real-time availability. Over South America, a total of 52528 grid points are used to produce the merged precipitation product, which combines 3B42RT with surface observations. The final merged product will have a resolution of $0.25^{\circ}$. The methodology for combining surface observations with TRMM precipitation estimates is presented in the next section.

\section{b. Merging technique}

The technique (hereafter referred to as MERGE) consists of the following sequence of steps. First, TRMM grid boxes in which surface observations are present are identified, as shown in Fig. 2. Note that at the observation point, the TRMM data are not used, so that maximum weight is given to the observation value. Following Koch et al. (1983), who suggest that the distance between the data to be interpolated should not exceed the final grid resolution (i.e., $0.25^{\circ}$ ), TRMM data are not considered for the two rows of grid boxes adjacent to the observation point. The total number of points around the observation points where TRMM is not considered is 24 , and the resulting map is shown in Fig. 2b.
A list is then generated with the precipitation amount, geographic location (latitude-longitude), and an assigned station identifier (33333 has been chosen to represent satellite data) for the remaining TRMM grid boxes (see Fig. 2b), followed by the surface observations (Fig. 3).

Surface observations and TRMM precipitation estimates are then interpolated onto a regular grid using the Barnes objective analysis method (Barnes 1973).

\begin{tabular}{|c|c|c|c|c|}
\hline \multirow{5}{*}{$\begin{array}{l}\mathbf{T} \\
\mathbf{R} \\
\mathbf{M} \\
\mathbf{M}\end{array}$} & ID & latitude & longitude & prec. \\
\hline & 33333 & -49.875 & -82.875 & 3.3 \\
\hline & 33333 & -49.625 & -82.875 & 22.1 \\
\hline & $\cdots$ & $\cdots$ & $\cdots$ & $\cdots$ \\
\hline & $\cdots$ & $\cdots$ & $\cdots$ & $\cdots$ \\
\hline & 83849 & -25.513 & -49.171 & 32.0 \\
\hline $\mathbf{O}$ & 83780 & -23.615 & -46.667 & 14.0 \\
\hline B & $\ldots$ & $\ldots$ & $\ldots$ & $\ldots$ \\
\hline $\mathbf{S}$ & $\ldots$ & $\ldots$ & $\ldots$ & $\ldots$ \\
\hline
\end{tabular}

FIG. 3. The 24-h accumulated TRMM precipitation combined with observations, showing a sample section of the list of station IDs created after the precipitation merge. 
- grid point

- Grid Point to Evaluate

- Station Location

Radius of Influence

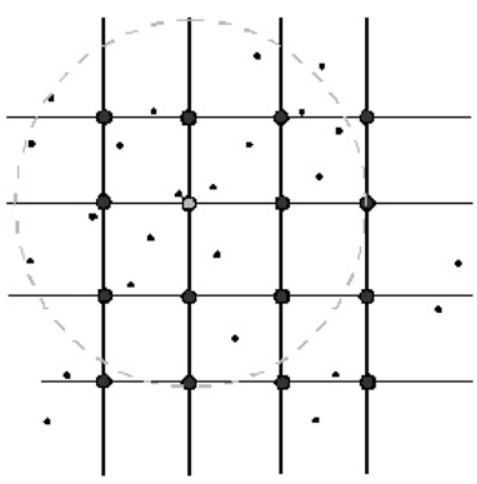

FIG. 4. Section of the domain where the Barnes objective analysis is applied, illustrating the different elements used in the method [General Meteorological Package (GEMPAK) online tutorial; information online at http://www.unidata.ucar.edu/software/gempak/ tutorial/barnes.html].

\section{c. Barnes objective analysis}

The precipitation was interpolated using successive corrections of the Barnes scheme (Barnes 1973; Koch et al. 1983), which typically requires two steps.

The objective analysis scheme is depicted in Fig. 4. Weights $\left(W_{n}\right)$ are given to each station within a radius $R$ as a function of distance $\left(x_{n}, y_{n}\right)$ to a grid point $(i, j)$ :

$$
W_{n}=\exp \left(-\frac{d_{n}^{2}}{R^{2}}\right)
$$

where $d$ is the distance between the station and a grid point and $R$ is the radius of influence.

The first guess is then calculated as

$$
g_{1}(i, j)=\frac{\sum_{n=1}^{N} W_{n} S\left(x_{n}, y_{n}\right)}{\sum_{n=1}^{N} W_{n}},
$$

where $S\left(x_{n}, y_{n}\right)$ are the observation values within the radius of influence. A correction term is then added to the first step by introducing a convergence parameter $(\gamma)$ that controls the amount of smoothing, determined by

$$
g_{2}(i, j)=g_{1}(i, j)+\frac{\sum_{n=1}^{N} W_{n}^{\prime}\left[S\left(x_{n}, y_{n}\right)-S^{1}\left(x_{n}, y_{n}\right)\right]}{\sum_{n=1}^{N} W_{n}^{\prime}},
$$

where $S^{1}\left(x_{n}, y_{n}\right)$ is the value calculated at the observation point $\mathrm{n}$ through bilinear interpolation of the four adjacent grid points found in the same iteration. Here, $W^{\prime}$ is the original weight corrected by gamma and is given by

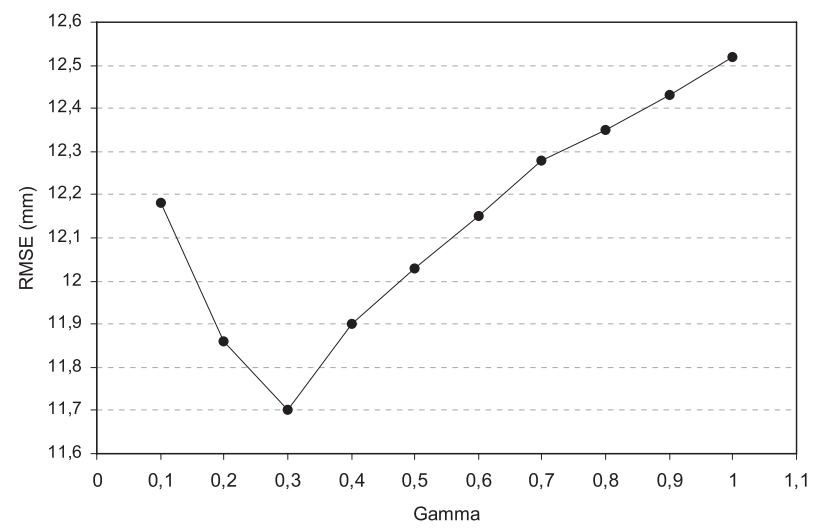

FIG. 5. RMSE calculated at different values of the gamma parameter.

$$
W_{n}^{\prime}=\exp \left(-\frac{d_{n}^{2}}{\gamma R^{2}}\right)
$$

Values for the convergence parameter $(\gamma)$ can vary between 0 and 1 ; however, the values are generally assumed to vary between 0.2 and 0.5 according to many studies (Koch et al. 1983; Mills et al. 1997; Accadia et al. 2003; Sinha et al. 2006). Several tests were performed to determine the optimum range for the gamma parameter to be used in this analysis. TRMM values at locations that coincided with the observation locations were interpolated to the TRMM grid points using nine different gamma values between 0.1 and 1.0. The experiment was repeated for 30 consecutive days and the RMSE was calculated for the entire period, given by

$$
\overline{\mathrm{RMSE}}=\frac{1}{30} \sum_{d=1}^{30} \sqrt{\frac{1}{N} \sum_{n=1}^{N}\left(\mathrm{TRMM}_{\text {ori }}-\mathrm{TRMM}_{\text {int }}\right)^{2},}
$$

where $N$ represents the number of stations, "ori" signifies the initial dataset, and "int" is the dataset interpolated through Barnes analysis.

The average RMSE as a function of gamma is shown in Fig. 5. A gamma value of 0.3 produces the lowest errors and falls within the range of lowest error (0.2-0.5) found in the literature; therefore, a value of 0.3 will be applied in this study.

\section{Analysis of results}

a. Cross validation with subsampling over the entire domain

This section investigates the potential improvements in the precipitation fields produced by the MERGE methodology when compared to interpolation of surface 


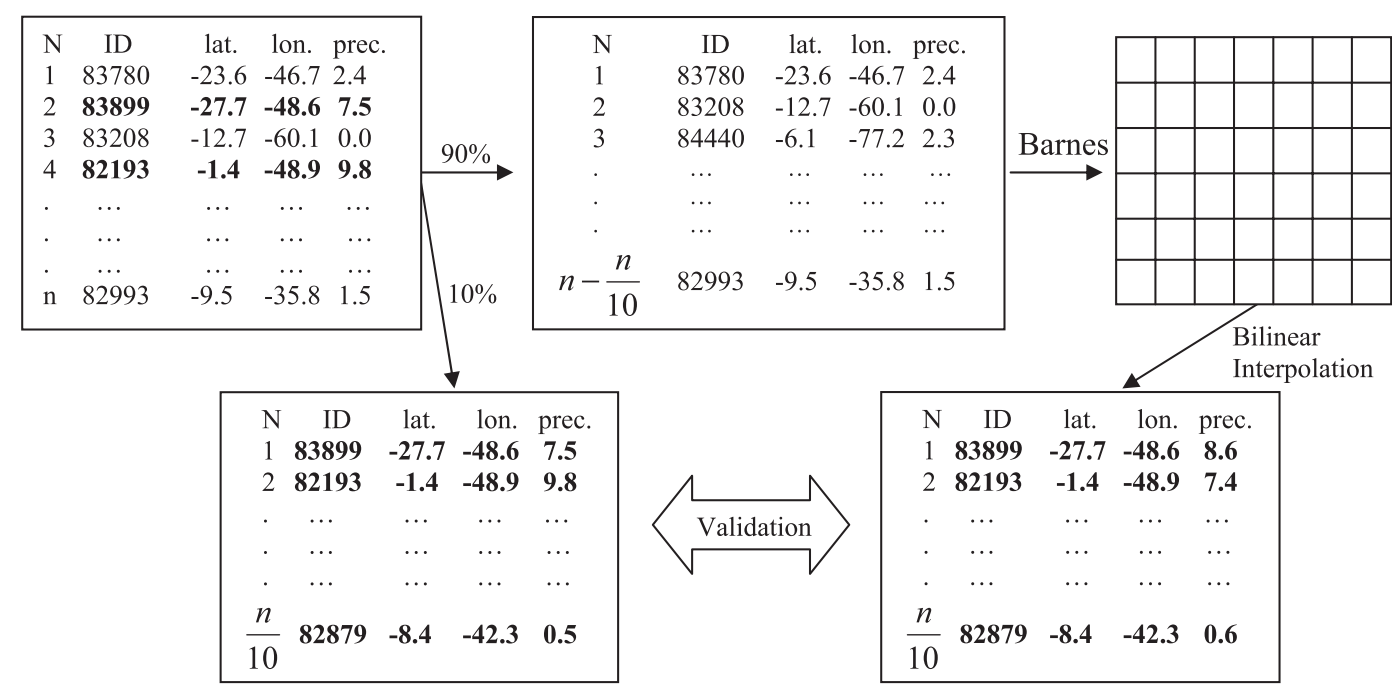

FIG. 6. Schematic diagram representing the evaluation methodology applied in this study.

observations (OBS). Observations were interpolated following the method of Caruso and Quarta (1998), after removing $10 \%$ of the observations subsampled randomly from the entire domain. The same procedure was applied for the proposed MERGE (OBS+TRMM) technique (Fig. 6). The OBS90, MERGE, and TRMM (3B42RT) fields were then evaluated at the locations where the $10 \%$ of observations were removed.

For this analysis, two trimesters of 2007 representing austral summer (January-March) and winter (JuneAugust) were selected. In general, precipitation over South America is high during the summer and lower during the winter. Several precipitation indices were used to validate the results, including the equitable threat score (ETS; Mesinger and Brill 2004), the bias, the probability of detection (POD), and the false alarm ratio (FAR), in addition to RMSE.

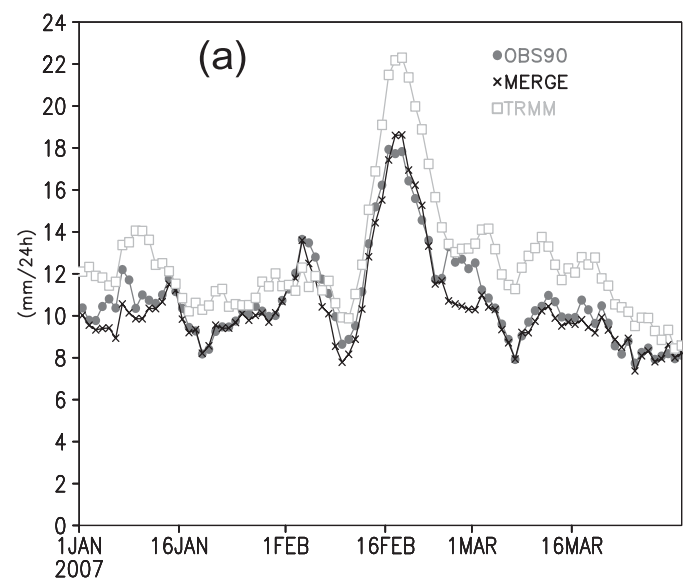

RMSE was computed for pentads (periods of five consecutive days) and its temporal evolution is shown in Figs. 7a (summer) and 7b (winter). OBS90 and MERGE show similar temporal error patterns for both trimesters. MERGE shows slightly lower errors during the summer (Fig. 7a), when the magnitude of the errors is large relative to the winter (Fig. 7b), due to the higher precipitation rates. However, during the winter, MERGE errors are lower than those of OBS90 on some days and higher on others. This behavior is probably associated with errors in the TRMM estimates, which are larger than those of both MERGE and OBS90.

The quantitative evaluation of the two datasets using the other statistical indices (ETS, POD, bias, and FAR) is shown in Fig. 8 for the entire period of study (2007 summer and winter trimesters). For ETS and POD, MERGE performs better than both OBS90 and TRMM,

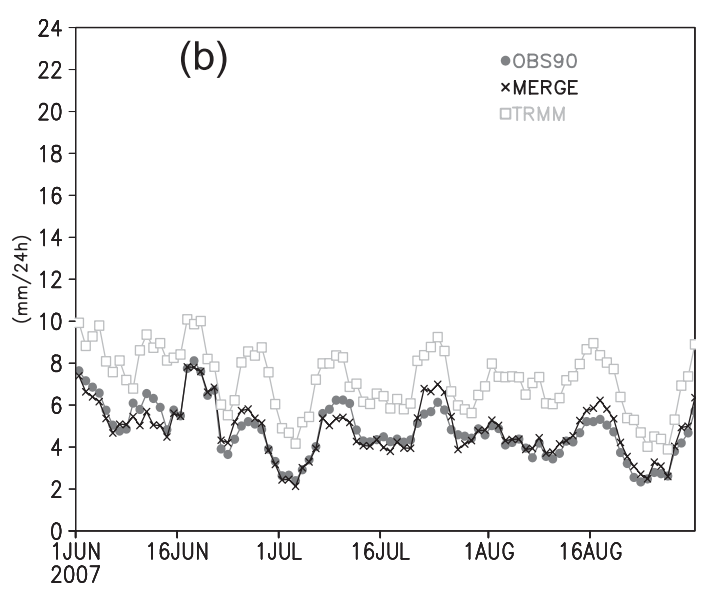

FIG. 7. Time series of RMSE pentads calculated for 2007 (a) summer and (b) winter trimesters. Calculations were performed considering a $10 \%$ random subsample over the entire domain. 

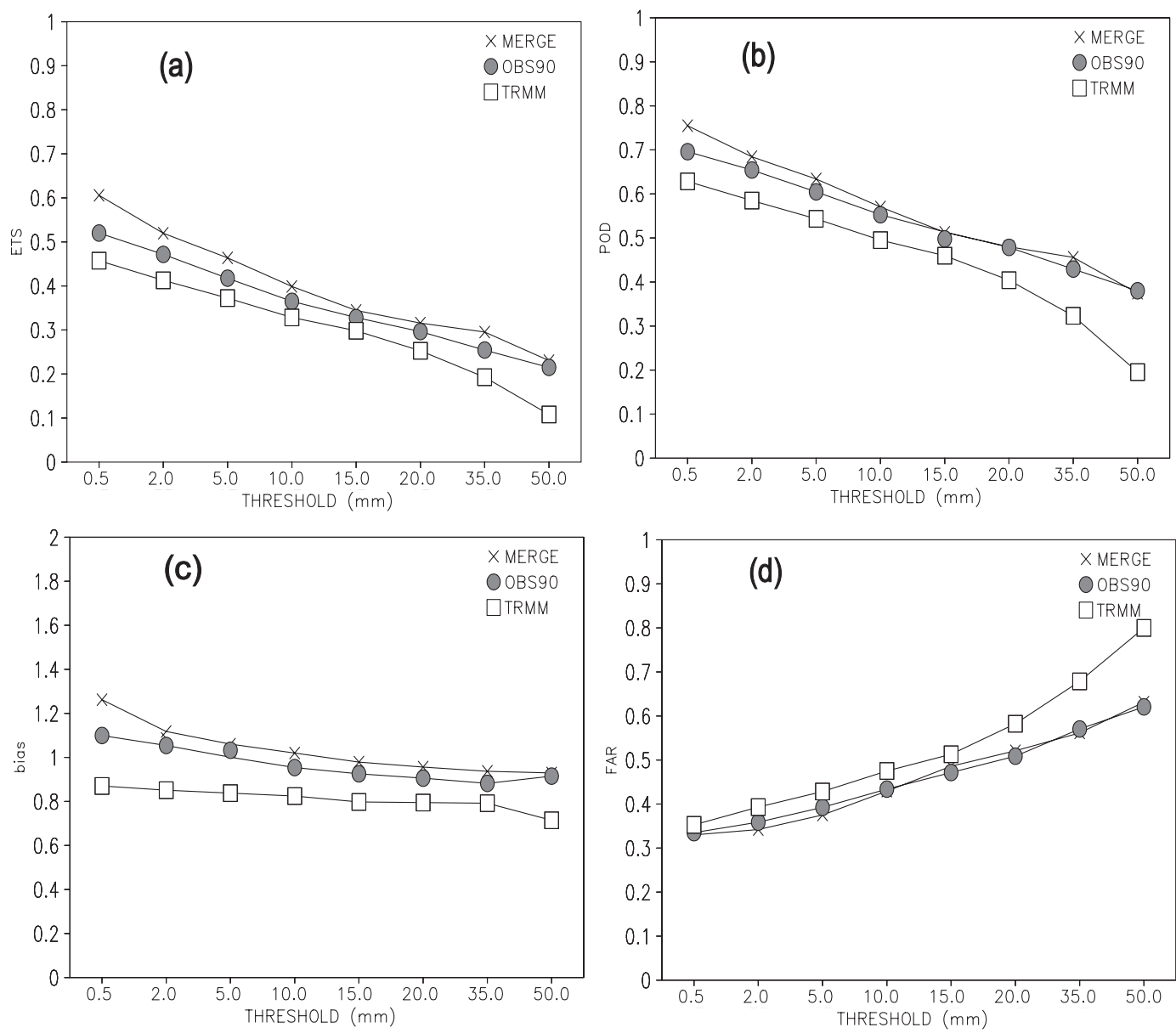

FIG. 8. Statistical indices (a) ETS, (b) POD, (c) bias, and (d) FAR computed for the entire period of study (summer and winter 2007) after randomly removing $10 \%$ of the observations over the whole domain.

mainly in the range of light to moderate precipitation (0.5-10.0 mm). However, for POD, MERGE and OBS90 show similar levels of performance for thresholds above $10.0 \mathrm{~mm}$. On the other hand, the bias score suggests that
MERGE has a slight tendency to overestimate precipitation, while OBS90 is closer to the observed amount, in particular above $2.0 \mathrm{~mm}$. The FAR results show that MERGE and OBS90 have the same level of performance
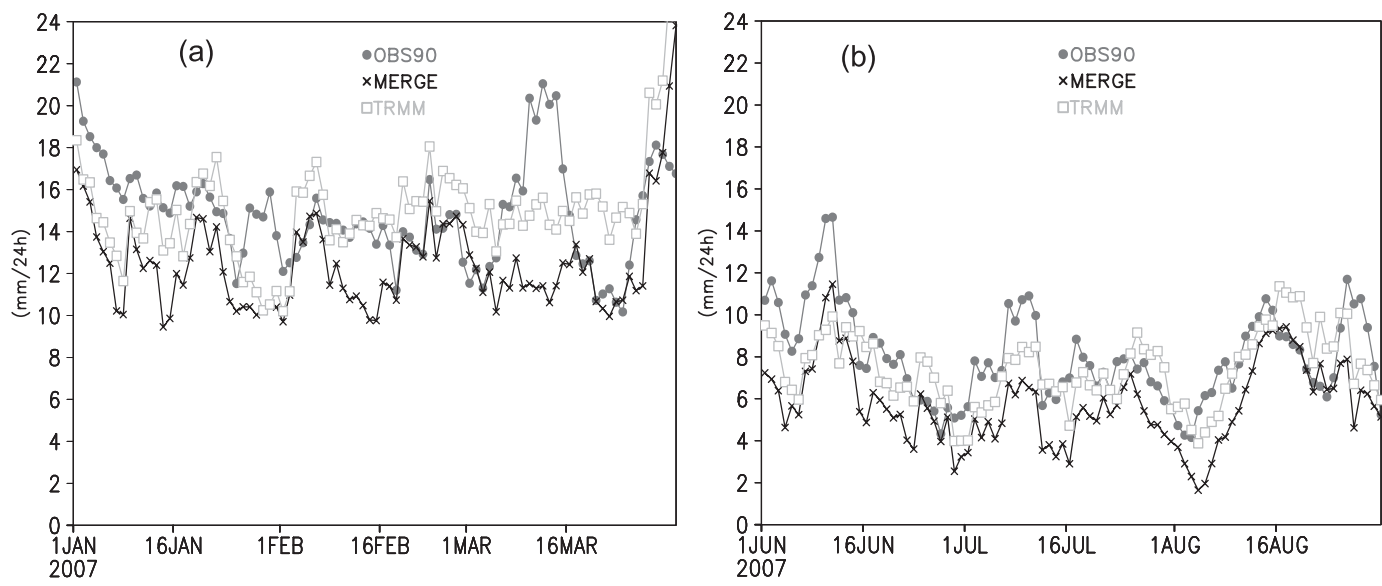

FIG. 9. Temporal evolution of the RMSE pentads for 2007 (a) summer and (b) winter trimesters after randomly removing $10 \%$ of the observations over the lower-density areas of the domain (west of $56^{\circ} \mathrm{W}$ ). 

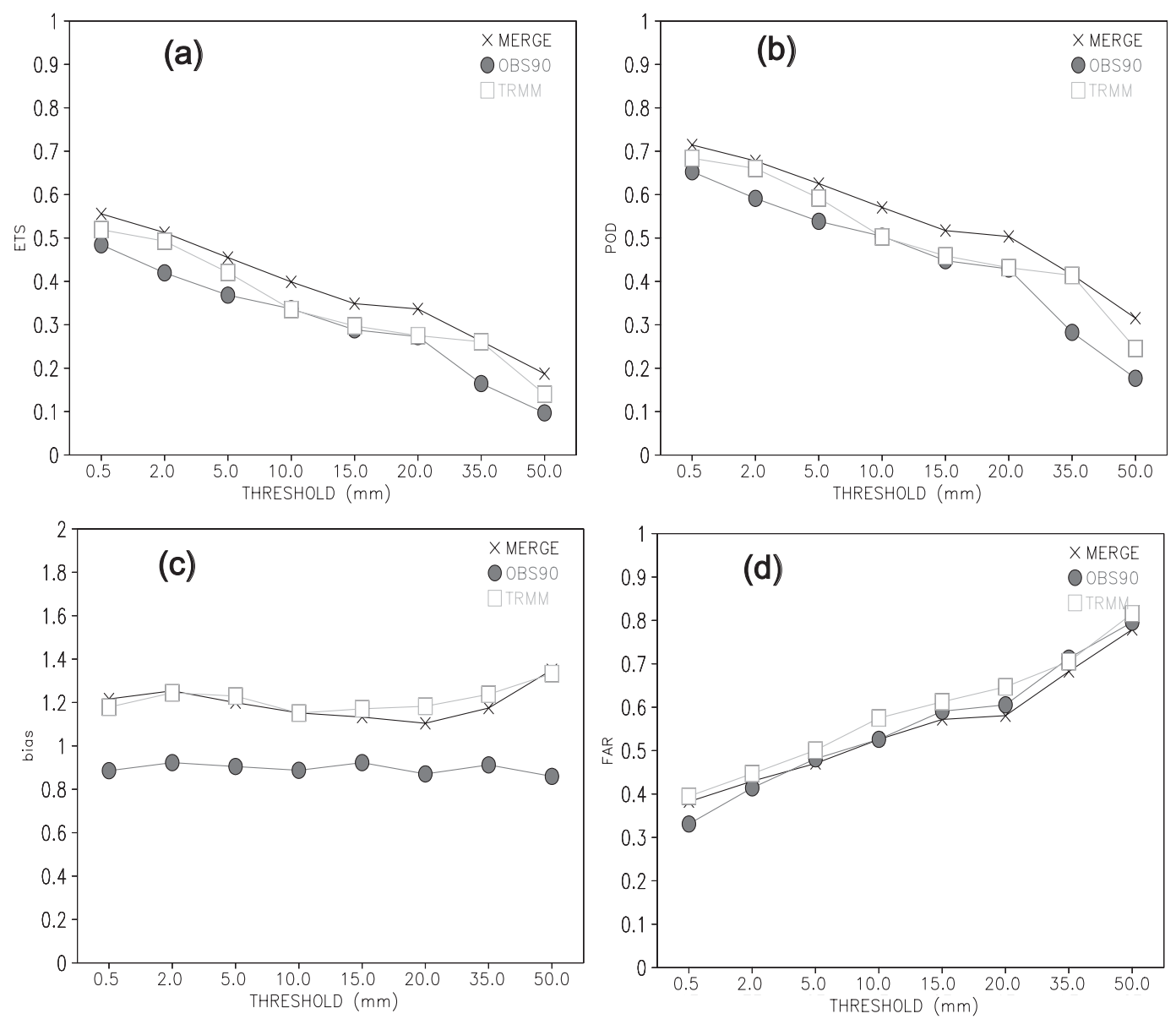

FIG. 10. Statistical indices (a) ETS, (b) POD, (c) bias, and (d) FAR computed for the entire period of study (summer and winter 2007) after randomly removing $10 \%$ of the observations over the lower-density areas of the domain (west of $56^{\circ} \mathrm{W}$ ).

when indicating that precipitation did not occur. It is observed that TRMM is the lowest quality precipitation estimate according to all indices. We conclude that validation with a random sample of $10 \%$ of the stations over the entire domain (South America) does not demonstrate significant improvement from using the MERGE technique compared to the interpolated observation fields (OBS90). Nevertheless, as shown in Fig. 1, the irregular spatial distribution of the observations is biased toward the continental edges, in particular over northeastern Brazil. Despite the $10 \%$ of the stations having been chosen randomly, about $92 \%$ of those were located in the high-density regions. Consequently, combining TRMM estimates with observations showed very little improvement relative to the interpolated surface observations.

\section{b. Cross validation with subsampling over selected areas}

To show how satellite information improves precipitation analysis over areas with few observations, we propose to randomly sample $10 \%$ of the stations only over regions with lower observation density (longitudes west of $56^{\circ} \mathrm{W}$ ).

The temporal evolution of RMSE pentads for summer (January-March) and winter (June-August) 2007 are shown in Figs. 9a and 9b, respectively. During the summer, MERGE shows a significant reduction in the errors relative to OBS90, in particular for January and March. Furthermore, during the winter, MERGE reduced the errors for the entire period except for a few days in August. The TRMM error is sometimes lower than that of OBS90, but always larger than that of MERGE.

Figures $10 a-d$ show the quantitative precipitation indices (ETS, POD, bias, and FAR) for the entire period of study (2007 summer and winter trimesters). MERGE presents more satisfactory ETS results when compared to OBS90 (Fig. 10a) for all precipitation thresholds. MERGE also has a better level of performance for all precipitation thresholds in detecting precipitation that actually occurred, as shown by POD (Fig 10b). While MERGE slightly overestimates precipitation for all thresholds, 


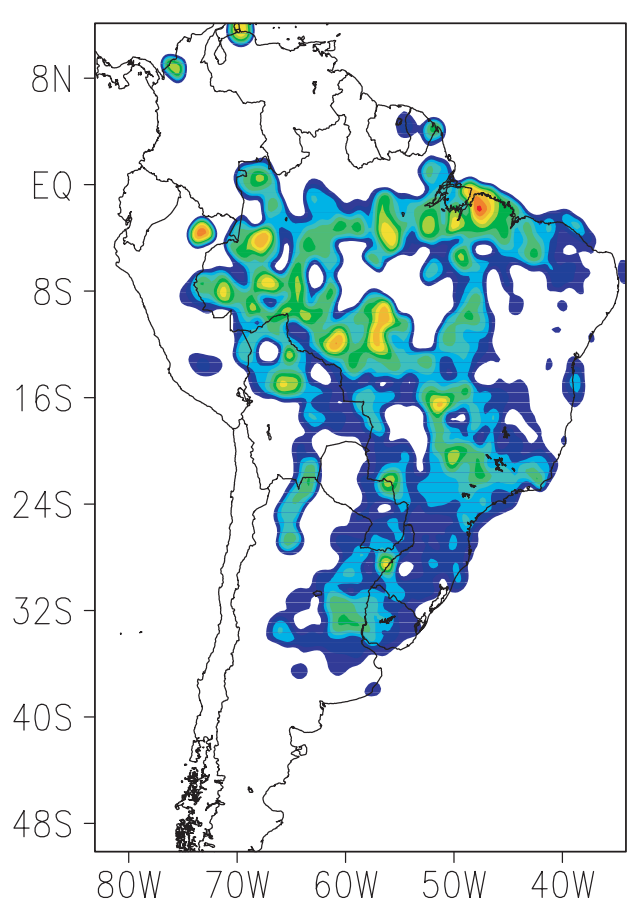

(a)

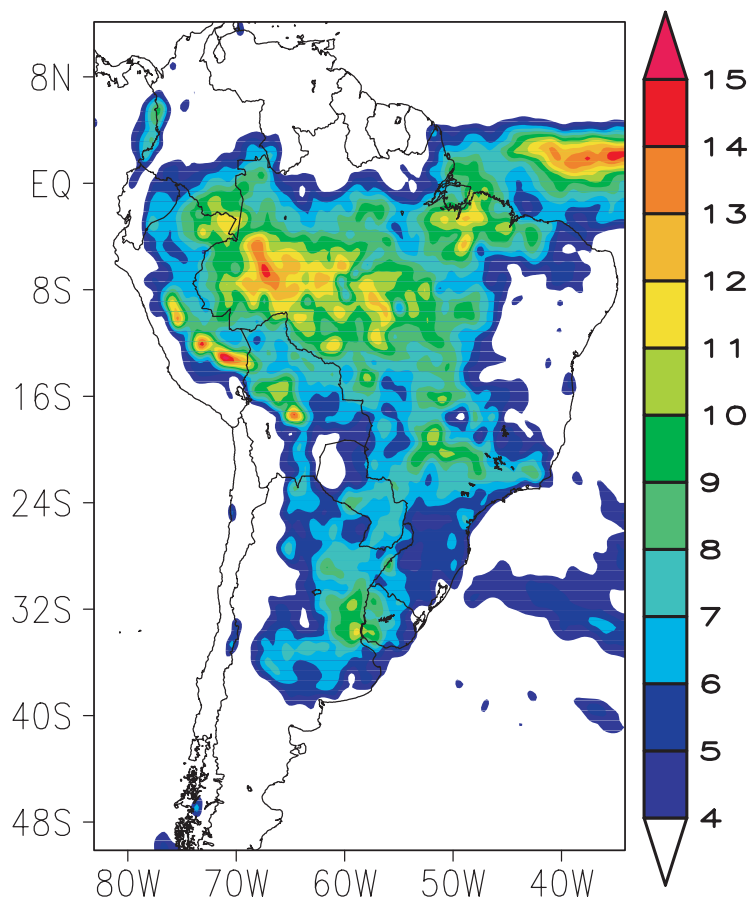

(b)

FIG. 11. Precipitation averaged over the summer trimester computed using (a) OBS90 and (b) MERGE.

as shown by the bias index (Fig. 10c), OBS90 tends to underestimate it. We suggest that this is associated with the intense convective activity that occurs in central South America and the Amazon region. The precipitation resulting from these convective complexes is scattered by the Barnes objective analysis.

There is a slightly higher number of false alarms (FAR) when comparing subsampling over a region with lower observation density (Fig. 10d) versus the entire domain (Fig. 8d) for both MERGE and OBS90. For all precipitation ranges, it is observed that the TRMM estimate is of higher quality than OBS90 but lower than MERGE.

The average precipitation for the summer trimester over the entire continent is shown in Fig. 11 for OBS90 (Fig. 11a) and MERGE (Fig. 11b). Regions with high observation density show very similar results, whereas in the regions with sparse observation networks, MERGE presents higher precipitation amounts. For instance, in central Amazonia, MERGE precipitation amounts range from 10 to $14 \mathrm{~mm}$ while OBS90 amounts are less than $4 \mathrm{~mm}$. This is largely due to the lack of information for the OBS90 product over that region, which causes the interpolated precipitation amounts to be low. Figure 12 shows the average precipitation over the entire continent in the winter trimester for OBS90 (Fig. 12a) and MERGE (Fig. 12b). Once again, MERGE presents higher (and more consistent with expected climatological values) precipitation over regions with a sparse observation network.

Another important feature when comparing MERGE with OBS90 is that with TRMM estimates it is possible to extend the precipitation analysis to the adjacent oceans, bringing some influence from remote observations over land, as shown in Figs. 11 and 12.

\section{Summary and conclusions}

A combination of TRMM satellite precipitation estimates with surface observations over the South American continent was performed for the 2007 summer and winter trimesters via a technique called MERGE. Two different approaches for the evaluation of the performance of this product against observations were tested: a crossvalidation subsampling of the entire continent and another subsampling of only areas with sparse observations. Over regions with a high density of surface stations, we found no significant improvements in the MERGE product (where in fact there is little contribution from TRMM) over simply interpolating the existing observations (OBS90). Nevertheless, the resulting analyses over low observation density regions (west of $56^{\circ} \mathrm{W}$ ) show substantial improvement in the MERGE product when compared with OBS90. Despite MERGE's higher FAR over regions with lower observation density (also found in the OBS90), 


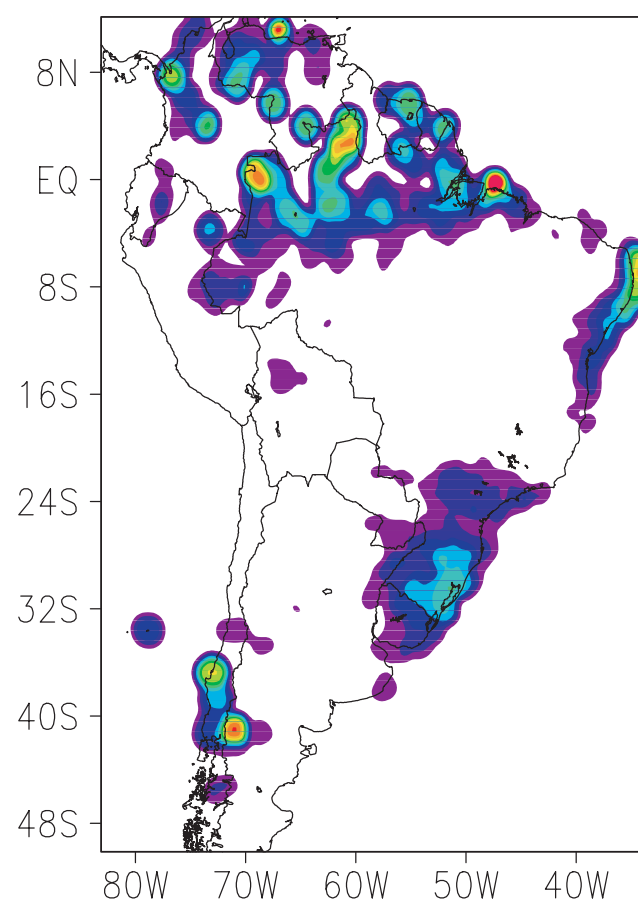

(a)

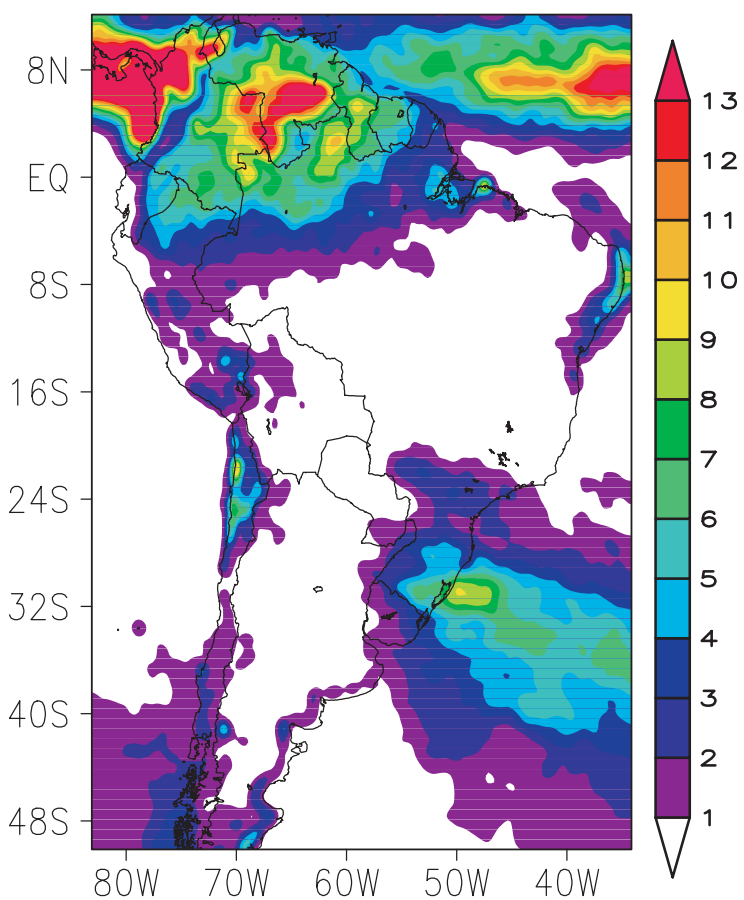

(b)

FIG. 12. Precipitation averaged over the winter trimester computed using (a) OBS90 and (b) MERGE.

MERGE has proven to be a valuable analysis tool in a regular grid for use in evaluating model results.

In summary, this study emphasizes two important aspects that merit attention in the evaluation of precipitation in atmospheric models, in particular at operational centers such as CPTEC/INPE: first, quick and efficient techniques to blend satellite and surface observations (such as the MERGE methodology presented in this paper) are needed in order for daily model evaluation to become practical at operational centers; second, evaluation of model results over large areas has to be performed with care, in particular over regions with an irregular and sparse observation network, such as the South American continent. Regions with different observation densities should be evaluated differently.

Nonetheless, this study reinforces the importance of remotely sensed precipitation estimates, in particular TRMM products, over regions with sparse ground information and the superiority of their combination with surface observations compared to the use of surface observations alone. The MERGE product has been used to validate all of the operational models at CPTEC/INPE since July 2008.

Acknowledgments. The authors are grateful to the FAPESP-Serra do Mar project (04/09469-0) and to Megan Marie Bela for helping to revise the English in this manuscript.

\section{REFERENCES}

Accadia, C., S. Mariani, M. Casaioli, A. Lavagnini, and A. Speranza, 2003: Sensitivity of precipitation forecast skill scores to bilinear interpolation and a simple nearest-neighbor average method on high-resolution verification grids. Wea. Forecasting, 18, 918-932.

Barnes, S. L., 1973: Mesoscale objective analysis using weighted time-series observations. NOAA Tech. Memo. ERL NSSL62, National Severe Storms Laboratory, Norman, OK, 60 pp. [NTIS COM-73-10781.]

Caruso, C., and F. Quarta, 1998: Interpolation methods comparison. Comput. Math. Appl., 35, 109-126.

de Goncalves, L. G. G., W. J. Shuttleworth, B. Nijssen, E. J. Burke, J. A. Marengo, S. C. Chou, P. Houser, and D. L. Toll, 2006: Evaluation of model-derived and remotely sensed precipitation products for continental South America. J. Geophys. Res., 111, D16113, doi:10.1029/2005JD006276.

Franchito, S. H., V. B. Rao, A. C. Vasques, C. M. E. Santo, and J. C. Conforte, 2009: Validation of TRMM precipitation radar monthly rainfall estimates over Brazil. J. Geophys. Res., 114, D02105, doi:10.1029/2007JD009580.

Huffman, G. J., and Coauthors, 2007: The TRMM Multisatellite Precipitation Analysis (TMPA): Quasi-global, multiyear, combined-sensor precipitation estimates at fine scales. J. Hydrometeor., 8, 38-55.

Koch, S. E., M. desJardins, and P. J. Kocin, 1983: An interactive Barnes objective map analysis scheme for use with satellite and conventional data. J. Climate Appl. Meteor., 22, 14871503.

Kummerow, C., and Coauthors, 2000: The status of the Tropical Rainfall Measuring Mission (TRMM) after two years in orbit. J. Appl. Meteor., 39, 1965-1982. 
Mesinger, F., and K. Brill, 2004: Bias normalized precipitation scores. Preprints, 17th Conf. on Probability and Statistics/20th Conf. on Weather Analysis and Forecasting/16th Conf. on Numerical Weather Prediction, Seattle, WA, Amer. Meteor. Soc., J12.6. [Available online at http://ams.confex.com/ams/pdfpapers/69561.pdf.]

Mills, G. A., G. Weymouth, D. Jones, E. E. Ebert, M. Manton, J. Lorkin, and J. Kelly, 1997: A National objective daily rainfall analysis system. BMRC Techniques Development Rep. 1, Melbourne, VIC, Australia, $30 \mathrm{pp}$.

Rozante, J. R., and I. F. A. Cavalcanti, 2008: Regional Eta Model experiments: SALLJEX and MCS development. J. Geophys. Res., 113, D17106, doi:10.1029/2007JD009566.
Sinha, S. K., S. G. Narkhedkar, and A. K. Mitra, 2006: Barnes objective analysis scheme of daily rainfall over Maharashtra (India) on a mesoscale grid. Atmósfera, 19, 59-76.

Valverde Ramírez, M. C., 2003: Use of neural network for analysis and forecast over the south and southeast Brazil. Ph.D. dissertation, Instituto Nacional de Pesquisas Espaciais (INPE), 238 pp. [Available online at http://urlib.net/sid.inpe.br/jeferson/ 2004/02.16.14.01.]

Vila, D. A., L. G. G. de Goncalves, D. L. Toll, and J. R. Rozante, 2009: Statistical evaluation of combined daily gauge observations and rainfall satellite estimates over continental South America. J. Hydrometeor., 10, 533-543. 
Copyright of Weather \& Forecasting is the property of American Meteorological Society and its content may not be copied or emailed to multiple sites or posted to a listserv without the copyright holder's express written permission. However, users may print, download, or email articles for individual use. 